\title{
Serum theophylline concentrations during multiple dosing with two sustained release methylxanthine preparations in normal subjects
}

\author{
JOHN G. PRIOR $\dagger$ \\ M.A., M.B., M.R.C.P. \\ D. BERRY* \\ L.R.I.C. \\ G. M. COCHRANE $\dagger$ \\ B.Sc., M.B., M.R.C.P. \\ †Department of Thoracic Medicine, and the *Poisons Unit, New Cross Hospital, London SE14 5ER
}

\begin{abstract}
Summary
In normal subjects, receiving multiple dosing regimes with Slophyllin and Phyllocontin in doses calculated to give either $4 \mathrm{mg} / \mathrm{kg}$ or $6 \mathrm{mg} / \mathrm{kg}$ theophylline free acid twice daily, serum theophylline concentrations were frequently less than $8 \mathrm{mg} / \mathrm{l}$. Accumulation of the serum theophylline trough concentration occurred during the first 3 days of multiple dosing, and was followed by subsequent stabilization or even decline in serum theophylline trough concentrations. Side effects were noted with both Slophyllin and Phyllocontin, but only on the higher dosage regimes; they occurred within $24-48 \mathrm{hr}$ of starting the drug, and tended to diminish if dosing was continued. The accumulation effect of serum theophylline concentrations may explain the timing of adverse effects, and should be avoided by starting methylxanthine therapy at a low dose. This may be increased after a few days. Further dosage adjustment may be necessary in some patients and should be facilitated by measurement of serum theophylline trough concentrations.
\end{abstract}

\section{Introduction}

Theophylline has been used in the management of bronchial asthma since 1936 (Tuft and Brodsky, 1936). At serum concentrations of $8-20 \mathrm{mg} / \mathrm{l}$ it is a safe and effective bronchodilator in adults (Jenne et al., 1972; Buelow, Larsson and Leideman, 1975). However, it is necessary for conventional oral theophylline preparations to be given 4-hourly to maintain serum theophylline concentrations in the therapeutic range (Weinberger and Bronsky, 1974), and sustained-release (SR) preparations, which reduce the need for such frequent dosing whilst

Correspondence: Dr J. Prior, Chest Clinic, New Cross Hospital, Avonley Road, London, S.E.14. maintaining serum theophylline concentrations in $\underset{\infty}{\circ}$ the therapeutic range, would be an advantage. The 응 aim of this study was to determine whether multiple dosing with 2 SR preparations Slophyllin (Rona os Laboratories) and Phyllocontin continus (Napp $\mathbb{O}$ Laboratories) in 2 different doses each given twice/ $\mathbb{\mathbb { D }}$ day, achieved serum theophylline concentrations in $\overline{0}$ the $8-20 \mathrm{mg} / \mathrm{l}$ range throughout the day, including $\stackrel{\Phi}{-}$ the morning serum theophylline trough conce $\vec{\varphi}$ tration.

\section{Materials and methods}

\section{Subjects}

Ten healthy volunteers, 5 male and 5 female, participated in the study. The age range was 21-39 $\propto$ years, and average weight was $69.9 \mathrm{~kg}$. One subject $\overrightarrow{\vec{P}}$ smoked a pipe consuming less than $2 \mathrm{oz}$ of tobacco/ 웅 week and another smoked an average of 10 cigar- $\vec{T}$ ettes/day. No subject had any evidence of cardiovascular, respiratory or liver disease. Informed consent was obtained from each subject.

\section{Drug products}

It was planned initially to study only Slophyllin; later the protocol was modified to include Phyllocontin. The study was therefore not randomized. 은 Slophyllin is anhydrous theophylline adsorbed on to $>$ a granular material incorporating a lipophilic wax to form small pellets which are placed in a gelatin $\tilde{N}$ capsule. Phyllocontin is aminophylline combined in a mixture of hydroxyethyl cellulose and a higher $\tilde{N}$ aliphatic alcohol, compressed in the form of a tablet. $\mathfrak{\omega}$

\section{Drug administration and dosage}

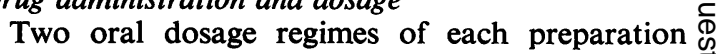
were used to give approximately $4 \mathrm{mg} / \mathrm{kg}$ (low dose, range $3.7-4.4 \mathrm{mg} / \mathrm{kg}$ ) or $6 \mathrm{mg} / \mathrm{kg}$ (high dose, range 
5.7-6.5 mg kg) twice daily. Each subject ingested a total of 13 doses of each preparation starting on the Saturday evening at 8 p.m. and subsequently at 12-hourly intervals for the remaining 12 doses, finishing at 8 p.m. on Friday. There was a 3-week interval between each regime. Low dosage regimes were always started first for ethical reasons.

\section{Blood sampling}

Blood samples were obtained by venepuncture before the morning dose ( 8 a.m.), and thereafter at 12 noon, 4 p.m. and 8 p.m. Sampling commenced on the Monday and finished at 8 p.m. on the Friday. The blood was centrifuged, stored at $-10^{\circ} \mathrm{C}$, and analysed for theophylline by a specific high pressure chromatographic method which excluded caffeine and common antibiotics (D. Berry and G. M. Cochrane, unpublished).

\section{Adverse effects}

Each subject was informed of the possible adverse effects to be expected, and each was asked to record the nature and timing of any adverse effect.

\section{Statistical analysis}

Analysis of the differences in numbers of serum theophylline trough concentrations $\geqslant 8 \mathrm{mg} / \mathrm{l}$ between the methylxanthine preparations was carried out using Fisher's Exact Test. Comparison of mean theophylline concentrations was carried out using an unpaired ' $t$ ' test.

\section{Results}

All 10 subjects completed the Slophyllin low dose regime, and 8 completed the Slophyllin high dose regime. Seven subjects entered and finished the low dose Phyllocontin regime, but only 5 entered the high dose regime. The other 5 subjects experienced side effects whilst on high dose Slophyllin and it was considered unethical to enter them into the Phyllocontin high dose regime.

\section{Theophylline concentrations during the day}

Figure 1 shows the mean values of serum theophylline concentrations during the 5-day period after dosing with each regime. There were no significant differences between the corresponding mean theophylline concentrations on the 2 low dose regimes or between the corresponding mean theophylline concentrations on the 2 high dose regimes (unpaired ' $t$ ' test).

On the low dose regimes, serum theophylline trough concentrations were frequently subtherapeutic. Concentrations $\geqslant 8 \mathrm{mg} / \mathrm{l}$ were attained on only 9 of 88 occasions in subjects on the low dose Slophyllin regime, and in 16 of 66 occasions on the low dose Phyllocontin regime. The differences between the preparations were not statistically

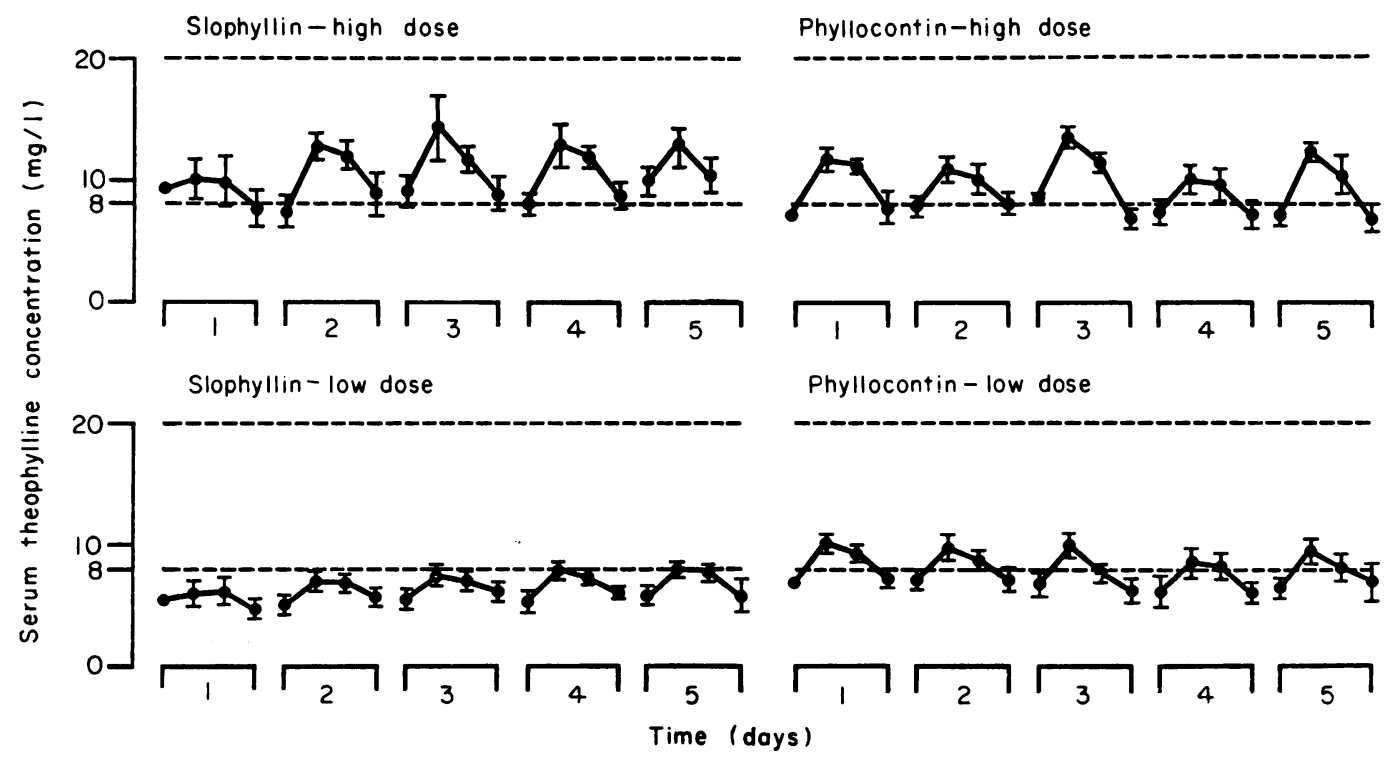

FIG. 1. Mean theophylline concentrations during sequential dosing with Phyllocontin and Slophyllin twice daily in 2 dosage regimes. The dotted lines indicate the serum theophylline concentrations over which maximal bronchodilatation occurs $(8-20 \mathrm{mg} / \mathrm{l})$. Bars represent \pm one standard error (1 s.e.). 
significant. On the higher dosage regimes, a trough concentration of $8 \mathrm{mg} / \mathrm{l}$ or more was attained on only 36 of 69 occasions in subjects on Slophyllin, and on 21 of 47 occasions in subjects on Phyllocontin. The differences were not significant. On days 4 and 5 , a serum trough concentration $\geqslant 8 \mathrm{mg} / \mathrm{l}$ was attained more frequently with Slophyllin (17 of 25 occasions) than with Phyllocontin ( 7 of 18 occasions), although these differences failed to reach statistical significance.

Only 3 of the 8 subjects on the high dose Phyllocontin regime and none of the subjects on the high dose Slophyllin regime had a serum theophylline trough concentration consistently $\geqslant 8 \mathrm{mg} / \mathrm{l}$ after $24 \mathrm{hr}$ of multiple dosing.

\section{Adverse effects}

Adverse effects did not occur in subjects on the low dose regimes. However, all but one subject taking the high dose Slophyllin regime experienced adverse effects, particularly nausea, anorexia and insomnia. Two female subjects had to withdraw after 2 days' multiple dosing because of this toxicity (peak theophylline concentrations of $21.0 \mathrm{mg} / \mathrm{l}$ and $23.0 \mathrm{mg} / \mathrm{l}$ on day 2). Two subjects developed nausea on the high dose Phyllocontin regime and another developed symptoms of oesophageal reflux $30 \mathrm{~min}$ after ingestion of Phyllocontin, even though in this subject peak theophylline concentrations were consistently $<15 \mathrm{mg} / \mathrm{l}$.

The adverse effects occurred during the first 24-48 hr and tended to diminish in subjects who continued taking the preparations.

\section{Accumulation in serum theophylline concentrations}

Accumulation of the serum theophylline trough concentrations during the first 3 days of multiple dosing, followed by subsequent stabilization or even decline of trough theophylline concentrations was seen in all but one subject on the Slophyllin regime and was most noticeable on the higher dosage regime. The accumulation effect was seen in 3

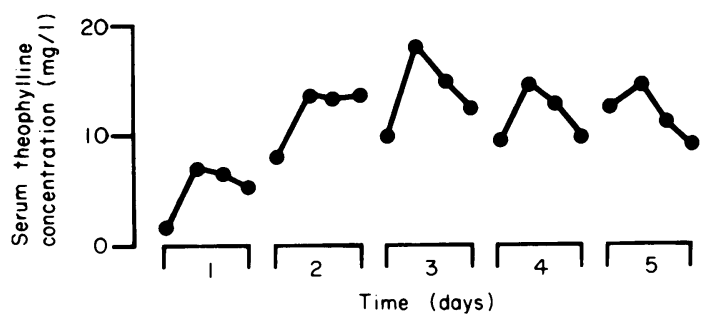

FIG. 2. Serum theophylline concentrations during sequential dosing with the high dose Slophyllin regime in one male subject, showing accumulation effect. subjects on the Phyllocontin high dose regime. $\frac{\$}{\mathbb{Q}}$ Figure 2 shows the accumulation effect in one male $\frac{\varrho}{c}$ subject during multiple dosing with high dose Slophyllin regime.

\section{Discussion}

The bronchodilator effect of theophylline is $\frac{\bar{\sigma}}{\bar{c}}$ related to its serum concentrations (Mitenko and $\stackrel{\varnothing}{\mathscr{Q}}$ Ogilvie, 1973). Maximal bronchodilatation occurs with serum theophylline concentrations in the 8-20 $\mathrm{mg} / \mathrm{l}$ range and serum concentrations of less $\overrightarrow{0}$ than $8 \mathrm{mg} / \mathrm{l}$ are associated with suboptimal broncho- $\overrightarrow{\vec{H}}$ dilatation (Buelow et al., 1975; Jenne et al., 1972) although recently it has been suggested that concen- $\bar{Q}$ trations $<8 \mathrm{mg} / \mathrm{l}$ may be effective in preventing 3 . nocturnal asthmatic symptoms (Fairfax et al., 1979). نे However, if theophylline preparations are used to manage bronchial asthma throughout the day, the of aim should be to keep the serum concentrations os above $8 \mathrm{mg} / \mathrm{l}$ at least during waking hours.

SR theophylline preparations have several theor- 을 etical advantages over conventional oral prep- $\rightarrow$ arations. Variation of serum theophylline concen- $\mathscr{\Phi}$ trations during the day should be less with SR $\frac{\mathbb{O}}{0}$ preparations than with conventional oral prep- $\frac{\mathbb{\Phi}}{3}$ arations (Weinberger, Hendeles and Bighley, 1978). O Dosing is less frequent and may improve complianceg (Sheen and Sly, 1979). However, the present studg $\vec{\emptyset}$ highlights an important problem with twice daile methylxanthine therapy; using doses similar to thos recommended by the manufacturers, serum theophylline trough concentrations over the 5-day multiple dosing period, with both Phyllocontin and Slophyllin, were frequently sub-therapeutic. There was no important difference in this respect between the 2 preparations tested. Therefore, it is likely that, on dosage regimes similar to those used in this study, many asthmatic patients would be undertreated for periods in the day. This might be predicted from the wide intra- and inter-subject variability in theophylline metabolism (Jacobs, Senior and Kessler, 1976). These observations underline the limitations of using fixed dosages of methylxanthines in the therapy of airways obstruction, and bear particular relevance to the design of therapeutic trials of SR methylxanthine preparations in asthma.

The phenomenon of accumulation of serum theophylline concentration during the first 3 days, followed by subsequent stabilization or decline in trough concentrations has not been noted previously. Although the relatively long half-life of theophylline, noted previously in normals (Caldwell and Lawrie, 1979) might explain the accumulation, it is unlikely to explain the subsequent stabilization or decline in trough concentrations. Shen, Fixley and Arzanoff (1978) found vatiations in serum theophylline halflife following chronic oral administration of con- 
ventional theophylline preparations and suggested that there was an initial inhibition, followed by an induction of theophylline metabolism during chronic oral dosing. Such a mechanism might explain the present observations. It is of interest that the adverse effects during therapy with both Phyllocontin and Slophyllin on the high dose regime occurred during the first 3 days of multiple dosing and then tended to subside. This has been noted in asthmatic patients taking oral Slophyllin twice daily (J. G. Prior and G. M. Cochrane, in preparation). Perhaps the accumulation effect might explain the timing of side effects. Starting therapy at a lower dose and gradually increasing it should minimize the early toxicity and might improve compliance.

The frequency of adverse effects with Slophyllin and Phyllocontin is higher in the present study than recorded in asthmatic patient (Prior and Cochrane, in prep.; Milledge and Hains, 1979). However, the normal subjects were not expecting any benefit from the preparations, whereas asthmatic patients would expect some relief from symptoms. This may have influenced the reporting of such effects.

This study emphasizes the importance of 'individualizing' theophylline dosage and provides a rational basis for initiation of twice daily SR methylxanthine therapy. Treatment should be started at the low dosage regime. The accumulation effect in trough theophylline concentrations would be minimized and a possible cause of early treatment default avoided. The dosage should be increased after a few days to the higher dosage regime. However, since serum theophylline concentrations may be sub-therapeutic in some patients, further dosage adjustment will be necessary. Measurement of the serum trough theophylline concentrations will facilitate final dosage adjustment and is essential if maximum benefit is to be obtained from twice daily SR methylxanthine preparations in the management of airways obstruction.

\section{Acknowledgments}

We thank Mr C. Panayi of Rona Laboratories for his continued help and encouragement, Mr F. House, Pharmacology Department, Guy's Hospital Medical School, London, for advice on statistics, and Miss J. Wright for typing the manuscript.

\section{References}

Buelow, K.R., Larsson, H. \& Leideman, T. (1975) Plasma theophylline level and ventilatory function in chronic obstructive pulmonary disease during prolonged oral treatment with choline theophyllinate. European Journal of Clinical Pharmacology, 8, 119.

Caldwell, J. \& Lawrie, C.A. (1979) The influence of certain environmental factors on theophylline half-life in man. Presented at British Pharmacological Society 18-19 Dec. 1979.

Fairfax, A.J., McNabb, W.R., Davies, H.J. \& SpIro, S.G. (1979) Double-blind cross-over study of slow release oral salbutamol and aminophylline at night for prevention of nocturnal asthma. Thorax, 34, 700.

Jacobs, M.H., Senior, R.M. \& Kessler, G. (1976) Clinical experience with theophylline. Journal of the American Medical Association, 235, 1983.

Jenne, J.W., Wyze, E., Rood, F.S. \& MacDonald, F.M. (1972) Pharmacokinetics of theophylline. Application to adjustment of the clinical dose of aminophylline. Clinical Pharmacology and Therapeutics, 13, 349.

Milledge, J.S. \& Hains, K. (1979) A comparison of slowrelease salbutamol and slow-release aminophylline in nocturnal asthma. Journal of International Medical Research, 7 (Suppl. 1), 106.

Mitenko, P.A. \& OGilvie, R.I. (1973) Rational intravenous doses of theophylline. New England Journal of Medicine, 289, 600 .

SheEN, A. \& SLY, R.M. (1979) Serum theophylline concentrations in asthmatic children. Annals of Allergy, 41, 327.

Shen, D.D., Fixley, M. \& Azarnoff, D.L. (1978) Theophylline bio-availability following chronic oral dosing of an elixir and two solid dosage forms. Journal of Pharmaceutical Science, 67, 916.

TUFT, L. \& BRODSKY, M.L. (1936) Influence of various drugs upon allergic reactions. Journal of Allergy, 7, 238.

WeINBERGER, M.M. \& BronsKy, E.A. (1974) Evaluation of oral bronchodilator therapy in asthmatic children. Journal of Pediatrics, 84, 421.

Weinberger, M., Hendeles, L. \& Bighley, L. (1978) The relation of product formulation to absorption of oral theophylline. New England Journal of Medicine, 299, 852. 